\title{
Risk factors for infection after endoscopic ultrasonography-guided drainage of specific types of pancreatic and peripancreatic fluid collections (with video)
}

\author{
Jintao Guo ${ }^{1} \cdot$ Linlin Feng ${ }^{1} \cdot \operatorname{Siyu}_{\mathrm{Sun}^{1}} \cdot \mathrm{Nan} \mathrm{Ge}^{1} \cdot \mathrm{Xiang}^{\mathrm{Liu}}{ }^{1} \cdot$ Sheng Wang $^{1} \cdot$ \\ Guoxin Wang ${ }^{1} \cdot$ Beibei Sun ${ }^{1}$
}

Received: 3 July 2015/Accepted: 3 September 2015/Published online: 22 January 2016

(C) The Author(s) 2016. This article is published with open access at Springerlink.com

\begin{abstract}
Background Endoscopic ultrasonography (EUS)-guided drainage is widely used for the treatment of specific types of peripancreatic fluid collections (PFCs). Infectious complications have been reported. It is recommended that the infection rate should be assessed by measuring risk factors. The objectives of this study were to measure whether the risk of infection after EUS-guided drainage was associated with patient- and procedure-related factors. Methods Eighty-three patients were eligible for inclusion from September 2008 to November 2012. EUS-guided
\end{abstract}

Electronic supplementary material The online version of this article (doi:10.1007/s00464-015-4557-3) contains supplementary material, which is available to authorized users.

Siyu Sun

sunsiyucmu@aliyun.com; sun-siyu@163.com

Jintao Guo

guojt@sj-hospital.org

Linlin Feng

fenglinlincmu@163.com

Nan Ge

yuefan_0225@163.com

Xiang Liu

liuxiangcmu@163.com

Sheng Wang

wangshengcmu@163.com

Guoxin Wang

wangguoxincmu@163.com

Beibei Sun

sunbei19@126.com

1 Endoscopy Center, Shengjing Hospital of China Medical University, No. 36, Sanhao Street,

Shenyang 110004, Liaoning Province, China drainage was performed in all patients. Infectious complications were observed, and data on patient- and procedurerelated factors were collected. Patient-related factors mainly included age, sex, etiology of PFC, and cyst location and diameter. Procedure-related factors mainly included approach of EUS-guided drainage and stent diameter. Separate multivariate logistic regression models for all EUS-guided drainage were carried out.

Results Complete EUS-guided drainage was achieved in all patients. A definitive diagnosis of infection after EUSguided drainage was made in seven patients. All seven patients had a history of acute pancreatitis, and the cyst diameters were all $>15 \mathrm{~cm}$. Three patients had diabetes mellitus.

Conclusions The cyst diameter was an independent risk factor for infection. Larger cysts with a diameter $>15 \mathrm{~cm}$ should perhaps be drained initially with multiple pigtail or a larger diameter self-expandable metal stents to try to avoid infection.

Keywords EUS-guided drainage - Peripancreatic fluid collections · Infection · Complications

PFC may complicate the course of pancreatitis, pancreatic surgery, or trauma. Several treatment options are available including surgery, external percutaneous drainage, and internal endoscopic drainage. EUS-guided drainage of PFC is a minimally invasive procedure and has become standard therapy worldwide for pancreatic pseudocyst and pancreatic walled-off necrosis [1,2].

Infection is one of the common complications after EUS-guided drainage, and it can prolong disease duration and increase length of hospital stay. The fever caused by infection can cause an imbalance in energy consumption 
and water and electrolyte balance. In the present study, we focused on the risk of infection after EUS-guided drainage. Our objectives were to measure whether the risk of infection after EUS-guided drainage was associated with patient- and procedure-related factors.

\section{Materials and methods}

\section{Patients}

We enrolled 83 consecutive patients who underwent EUSguided drainage for PFC at Shengjing Hospital of China Medical University from September 2008 to November 2012. Infections that occurred within 30 days after EUSguided drainage were diagnosed by a physician according to the classical symptoms of fever, positive culture of aspirated fluid, and white blood cell elevation. The indications for EUS-guided drainage were: (1) symptomatic PFC; (2) PFC in which the cystic wall was in contact with the gastric or duodenal wall on EUS; and (3) PFC that was resistant to conservative treatment. Exclusion criteria were: (1) acute PFC; (2) acute necrotic collections (ANC); (3) non-fluid walled-off necrosis; and (4) patients with suspected malignancy (Figs. 1, 2, 3).

\section{Ethics}

This study was approved by the Institutional Review Board and Ethics Committee of China Medical University. All patients voluntarily chose their therapeutic course and provided written informed consent for their participation in this study. Written informed consents were obtained from the parents or guardians of minors (age $<18$ years).

\section{Procedure}

All procedures were conducted by an experienced therapeutic endoscopist. The instruments used were a linear array echo-endoscope (EG3830UT; Pentax, Tokyo, Japan) with an adjustable ultrasonic frequency of $5,7.5$, or $10 \mathrm{MHz}$, in combination with an ultrasound scanner (EUB 6500; Hitachi, Tokyo, Japan). The cysts were carefully observed to ensure that no mural nodules or mass lesions were being overlooked; then, the puncture site was determined. A prerequisite for needle placement was that the gastric or duodenal wall should be in contact with the cystic wall at the puncture site. Power Doppler imaging was used to confirm that there were no interposed vessels at the puncture site. The initial puncture was accomplished with a 19-gauge needle (EUS N-19-T; Wilson-Cook Medical, Winston-Salem, NC, USA) guided by real-time EUS imaging. After withdrawing the inside needle stylet, some fluid was aspirated for routine cytological, biochemical, and microbiological analysis as well as culture.

A 0.035-inch guidewire (Jagwire; Boston Scientific, Natick, MA, USA) was inserted through the needle lumen into the cyst. When fluoroscopic imaging confirmed that the guidewire was sufficiently inserted, the needle was withdrawn; the guidewire was left in situ. Subsequently, a cystotome (10 Fr; Wilson-Cook Medical) was used to dilate the tract and create a large fistula. After dilation of the puncture tract, a double-pigtail stent $(8.5$ or $10 \mathrm{Fr}$; Endo-Flex GmbH, Voerde, Germany) was placed into the cyst cavity over the guidewire. The guidewire was then removed, and the cystic fluid was aspirated via the drainage tube. Finally, the echo-endoscope was removed and the drain was fixed at an adequate position.

Post-procedure, the patients were observed for a period of at least 7 days. Prophylactic antibiotic (ceftriaxone, $1 \mathrm{~g}$
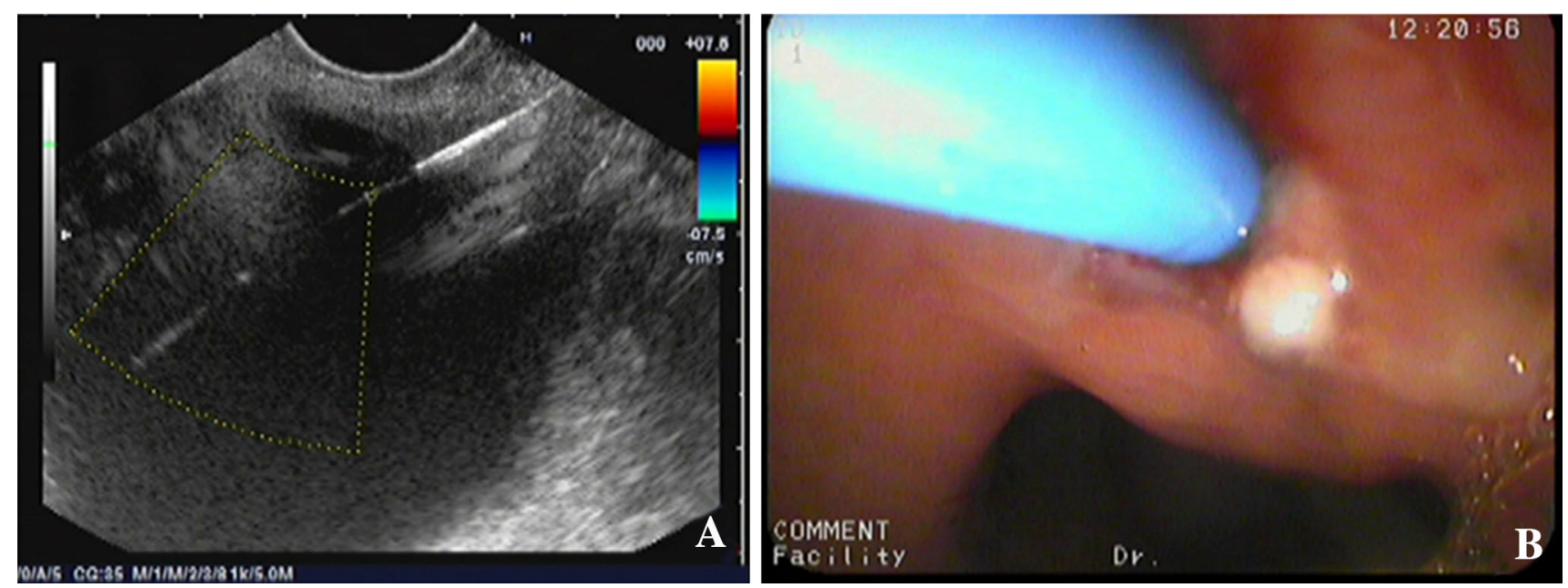

Fig. 1 A Pancreatic pseudocyst was observed by EUS. B EUS-guided drainage was performed transgastrically 

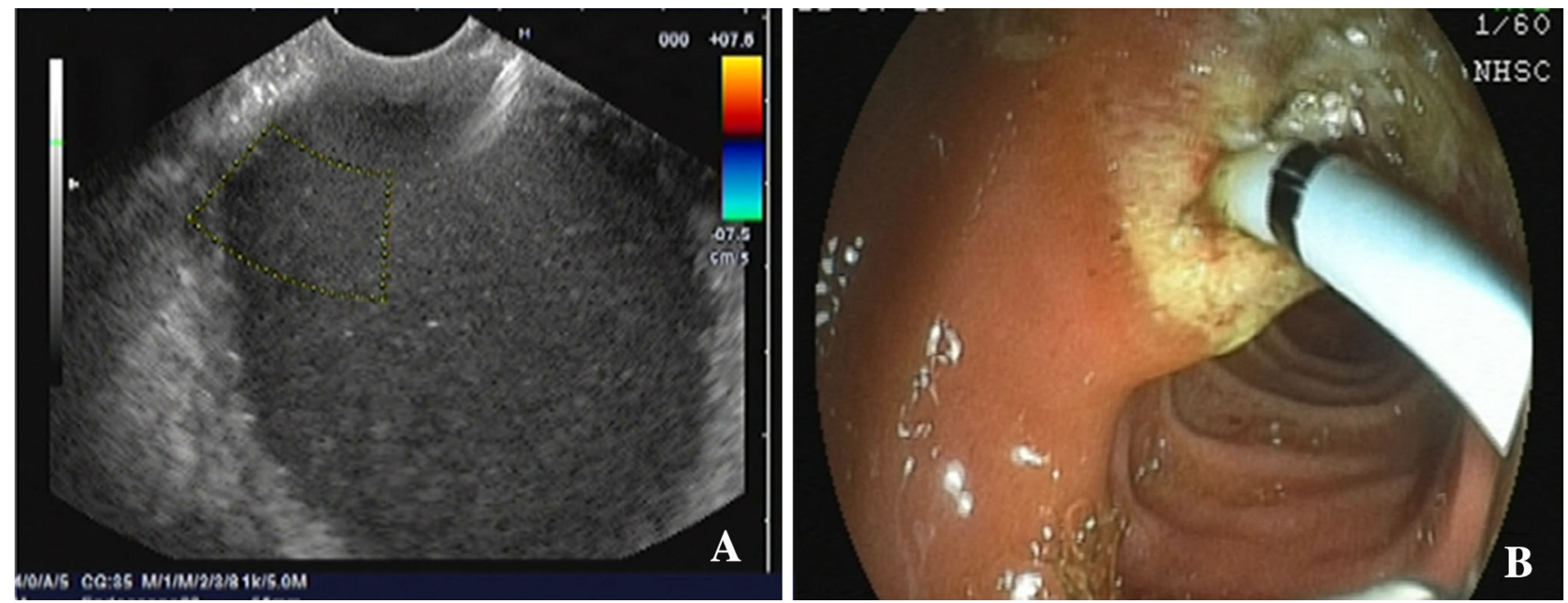

Fig. 2 A Pancreatic pseudocyst was observed by EUS. B EUS-guided drainage was performed transduodenally
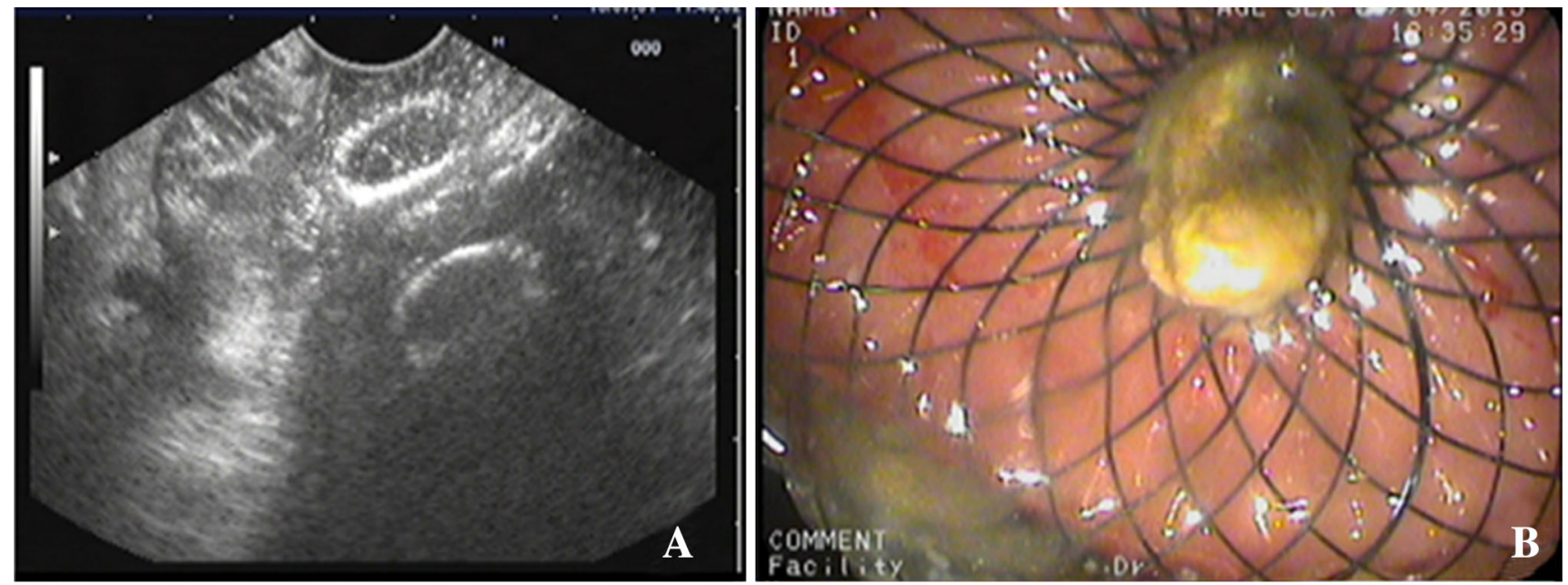

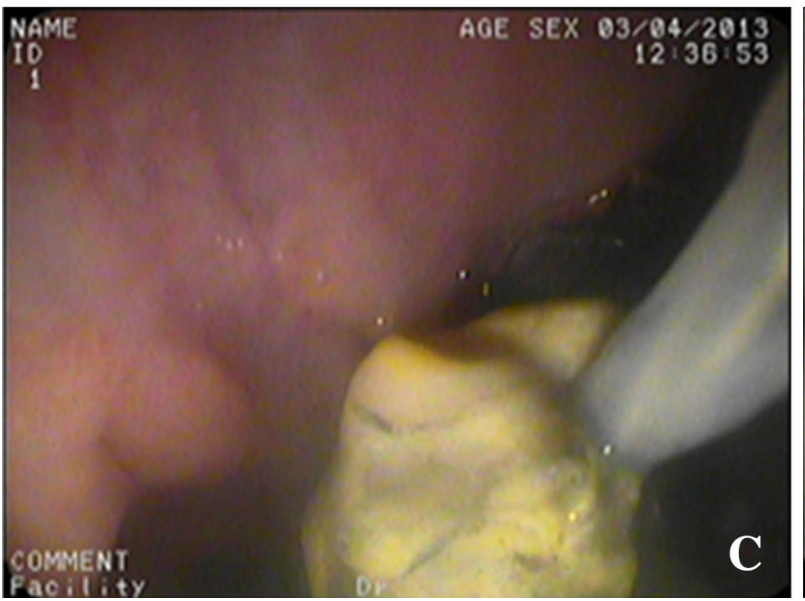

Fig. 3 A In EUS imaging, a double-flanged metal stent was placed transmurally between the walled-off necrosis and gastric wall. B, C There was much debris in the cyst. Direct endoscopic necrosectomy

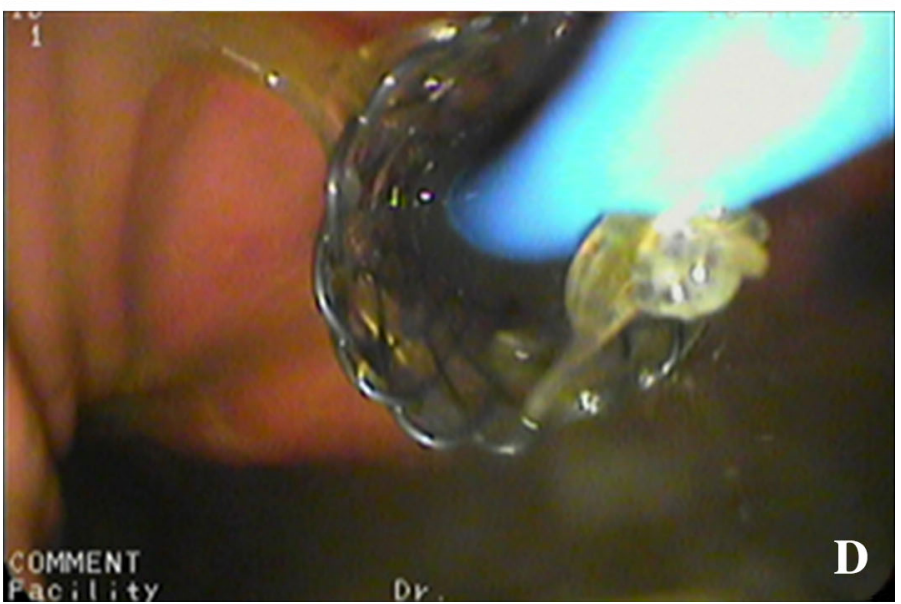

was performed though the metal stent. D After necrosectomy, a pigtail-type, nasobiliary drainage catheter $(7 \mathrm{Fr})$ was placed into the cyst 
IV) was given routinely twice daily for at least 2 days after the procedure. After placement of the double-pigtail stent, the patients were followed up clinically and radiologically. Computed tomography (CT) was done 7 days post-procedure, and then once monthly. The double-pigtail stent was removed after the patients became asymptomatic for a period of at least 4 weeks, and after confirming the absence of a cyst cavity by CT. A pseudocyst was deemed to be resolved if the CT revealed no collection at 3 months postprocedure.

Post-procedure, if the body temperature of patient rose above $38.0^{\circ} \mathrm{C}$ and persisted for $>48 \mathrm{~h}$, and the white blood cell count was $>10^{10} \mathrm{mmol} / \mathrm{L}$, an infection was assumed. Once infection occurred, dilation of the tract by wire-guided balloon up to $12-15 \mathrm{~mm}$ was conducted. After dilation of the puncture tract, another two or three double-pigtail stents (10 Fr; Endo-Flex $\mathrm{GmbH}$ ) were placed in the cyst cavity. A pigtail-type nasobiliary drainage catheter (7 Fr; Wilson-Cook Medical) was sometimes placed into the cyst. Then, the cysts were routinely lavaged with normal saline. If there were much debris in the cyst, metal stents (10 mm diameter; Micro Technique, Nanjing, China) were used instead of double-pigtail stents. Direct endoscopic necrosectomy was performed though the metal stent. Conversely, if the cyst did not resolve or the symptoms persisted, alternative treatments such as percutaneous drainage or surgical intervention were considered.

\section{Statistical analysis}

Separate multivariate logistic regression models for all EUS-guided drainage were carried out. For the logistic regression, the normality of residuals was tested by probability plots. Statistical analysis was performed with SPSS version 19.0 (SPSS Inc., Chicago, IL, USA). $P<0.05$ was considered to be statistically significant.

\section{Results}

From September 2008 to November 2012, 83 patients (45 male and 38 female, median age: 47.9 years, range 10-80 years) with PFCs were included. The baseline characteristics are presented in Table 1.

The etiology of the PFCs was acute pancreatitis in 40 (48.2\%) patients, chronic pancreatitis in 26 (31.2\%), external injury and surgery in $14(16.9 \%)$, postchemotherapy in one $(1.2 \%)$, and idiopathic in the remaining two $(2.4 \%)$. Sixty patients had a single cyst, and 23 had multiple cysts. The cysts were located in the pancreatic head in 19 patients, the body in 24 , and the tail in the remaining 40 (only the cysts that underwent EUSguided drainage were included). Eleven patients with cysts
Table 1 Baseline characteristics of patients who underwent EUSguided drainage

\begin{tabular}{ll}
\hline Total no. of patients & 83 \\
Age (year) & 47.9 \\
Male: female & $45: 38$ \\
Etiology & \\
Acute pancreatitis & 40 \\
Chronic pancreatitis & 26 \\
Trauma and surgery & 14 \\
Others & 3 \\
Location of the cyst & \\
Head & 19 \\
Body & 24 \\
Tail & 40 \\
Cyst diameter (cm) & 11 \\
Cyst wall thickness (mm) & 5 \\
Infected pseudocyst before EUS-guided drainage & 8 \\
Diabetes mellitus & 12 \\
\hline
\end{tabular}

in the tail region had compartmental portal hypertension. The median largest diameter of the cysts was $11 \mathrm{~cm}$ (range $6-26 \mathrm{~cm})$.

The puncture was attempted via the transgastric approach in 76 patients and via the transduodenal approach in seven. The median thickness of the cystic and gastric/duodenal walls was $5 \mathrm{~mm}$ (range $3-10 \mathrm{~mm}$ ). EUSguided drainage was successful in all patients. The clinical symptoms resolved in most patients after a median duration of 2 days (range 1-7 days). Seventeen patients had fever after EUS-guided drainage. The fever resolved within $48 \mathrm{~h}$ in ten patients following the administration of broadspectrum antibiotics. A definite diagnosis of infection after EUS-guided drainage was made in seven other patients. All seven patients had a case history of severe acute pancreatitis, and all cyst diameters were $>15 \mathrm{~cm}$. Three patients had diabetes mellitus. Following dilation and stent change, the body temperature of all patients decreased to normal. No other treatment options were considered.

Univariate analysis of the risk factors for infection after EUS-guided drainage is presented in Table 2. In addition, multivariate analysis is presented in Table 3. Complete resolution of pseudocysts was documented in all 83 cases. The indwelling double-pigtail stent was removed in all cases after a median duration of 11 weeks (range 4-18 weeks). After median follow-up of 31 months (range 5-67 months), recurrence of PFC was observed in one patient. This patient had chronic pancreatitis, which was managed with another session of EUS-guided drainage. After median follow-up of 31 months, all patients who did not develop a cystic fluid infection improved without any clinical sequelae. 
Table 2 Univariate analysis of the risk factors for infection after EUS-guided drainage
Table 3 Multivariate analysis of the risk factors for infection after EUS-guided drainage

\begin{tabular}{|c|c|c|}
\hline Variable & Infection after EUS-guided drainage & $P$ \\
\hline \multicolumn{3}{|l|}{ Age (year) } \\
\hline$<50$ & $3 / 45(6.7 \%)$ & \multirow[t]{2}{*}{0.815} \\
\hline$\geq 50$ & $4 / 38(10.5 \%)$ & \\
\hline \multicolumn{3}{|l|}{ Gender } \\
\hline Male & $3 / 45(6.7 \%)$ & \multirow[t]{2}{*}{0.815} \\
\hline Female & $4 / 38(10.5 \%)$ & \\
\hline \multicolumn{3}{|c|}{ Combined with diabetes mellitus } \\
\hline Yes & $3 / 12(25.0 \%)$ & \multirow[t]{2}{*}{0.095} \\
\hline No & $4 / 71(5.6 \%)$ & \\
\hline \multicolumn{3}{|l|}{ Etiology } \\
\hline Acute pancreatitis & $7 / 40(17.5 \%)$ & \multirow[t]{4}{*}{$0.042^{*}$} \\
\hline Chronic pancreatitis & $0 / 26$ & \\
\hline Trauma and surgery & $0 / 14$ & \\
\hline Others & $0 / 3$ & \\
\hline \multicolumn{3}{|l|}{ Multiple cysts } \\
\hline No & $4 / 60(6.7 \%)$ & \multirow[t]{2}{*}{0.621} \\
\hline Yes & $3 / 23(13.0 \%)$ & \\
\hline \multicolumn{3}{|l|}{ Cyst location } \\
\hline Head & $0 / 19$ & \multirow[t]{3}{*}{0.303} \\
\hline Body & $3 / 24(12.5 \%)$ & \\
\hline Tail & $4 / 40(10.0 \%)$ & \\
\hline \multicolumn{3}{|l|}{ Cyst diameter $(\mathrm{cm})$} \\
\hline$<15 \mathrm{~cm}$ & $0 / 66(0 \%)$ & \multirow[t]{2}{*}{$<0.000^{*}$} \\
\hline$\geq 15 \mathrm{~cm}$ & $7 / 17(41.1 \%)$ & \\
\hline \multicolumn{3}{|c|}{ Approach of EUS-guided drainage } \\
\hline Transgastric & $76 / 83(91.6 \%)$ & \multirow[t]{2}{*}{0.408} \\
\hline Transduodenal & $7 / 83(8.4 \%)$ & \\
\hline \multicolumn{3}{|l|}{ Stent diameter } \\
\hline $8.5 \mathrm{Fr}$ & & \multirow[t]{2}{*}{0.938} \\
\hline $10 \mathrm{Fr}$ & & \\
\hline
\end{tabular}

\begin{tabular}{llllllll}
\hline Variable & $B$ & SE & Wals & $d f$ & $P$ & Exp (B) & Exp (B); 95 \%CI \\
\hline Etiology & 0.615 & 0.584 & 1.11 & 1 & 0.292 & 1.85 & $0.589-5.815$ \\
Cyst diameter & -3.437 & 1.183 & 8.438 & 1 & $0.004 *$ & 0.032 & $0.003-0.327$ \\
\hline
\end{tabular}

$S E$ standard error, $C I$ confidence intervals for proportions

* Statistically significant

\section{Discussion}

PFC can develop secondary to fluid leakage or liquefaction of pancreatic necrosis. PFCs are also seen in association with acute and chronic pancreatitis, abdominal trauma, and surgery [3-5]. EUS-guided drainage of PFC has become first-line therapy at many centers [3-6]. This is due to the ability of EUS to assess wall thickness, identify major vessels, and find the closest access to the fluid cavity [7-9]. The procedure creates an internal fistula; thus, it avoids the inconvenience of external drainage and the risk of cutaneous fistula formation. EUS-guided drainage has a technical success rate $>90 \%$ and a treatment success rate of 75-90\%, depending on the pseudocyst characteristics [1013]. EUS-guided drainage is also less invasive than surgery and avoids adverse events related to percutaneous drainage $[11,14]$. Furthermore, EUS can easily identify and distinguish the nature of the lesion, even if there is no noticeable bulge into the gastric lumen. In addition, the dynamic movements of the puncture needle during the procedure 
can be controlled and tracked longitudinally by the realtime image; thus, avoiding any inadvertent complications related to needle puncture. The additional advantage of color Doppler US is that it aids identification of the interposed vessels located along the course of the needle puncture, thus insuring their avoidance. Therefore, EUSguided transmural puncture is significantly more reliable, dependable, and safer than the conventional techniques.

Infection is one of the complications after EUS-guided drainage, which may prolong the length of stay and increase the cost. For these reasons, it is important to establish the risk factors for infection after EUS-guided drainage. Our objective was to determine whether the risk of infection after EUS-guided drainage was associated with patient- and/or procedure-related factors.

Procedure-related risk factors for infection after EUSguided drainage have been reported in several studies. A recent study by Puri et al. [15] reported that dilatation of a fistulous tract up to $15 \mathrm{~mm}$ in length and the simultaneous use of stents and a nasocystic tube, combined with normal saline irrigation, improved the outcome of the technique. Their outcome for cyst resolution was $87 \%$, which was superior to other studies [16-18]. Another study by Ali et al. [19] reported in patients with pseudocysts with viscous fluid containing solid debris that EUS-guided endoscopic drainage via a nasocystic drain alongside transmural stents resulted in a lower stent occlusion rate and better short-term clinical outcomes, compared with patients who underwent cyst drainage via transmural stents alone. Takao et al. [20] reported that transenteric drainage of pancreatic pseudocysts using a novel, lumen-apposing metal stent was accomplished with a high degree of technical and clinical success.

In the present study, after dilation of the puncture tract, an 8.5-10-Fr double-pigtail stent was placed into the cyst cavity. The procedure was successful in all patients. Neither the diameter of double-pigtail stent nor the approach of EUS-guided drainage (transgastric or transduodenal) significantly affected the incidence rate of infection ( $P=0.938$ and $P=0.408$, respectively).

Acute pancreatitis was a relevant independent risk factor for infection after EUS-guided drainage $(P<0.05)$. This may have been due to some pancreatic fluid collection after acute necrotizing pancreatitis, containing necrotic tissue and debris, which could not be evacuated by a single plastics stent. Cyst diameter was also an independent risk factor for infection. Perhaps the increased risk of infection was because more time was needed for cyst shrinkage.

Several investigators have demonstrated that pseudocyst drainage complicated by infection can be improved by additional stent placement that enhances drainage [21]. Therefore, we placed another two or three double-pigtail stents (10 Fr in diameter and $5 \mathrm{~cm}$ in length) into the cysts.
In two cases, double-flanged metal stents were used instead of double-pigtail stents. Direct endoscopic necrosectomy was performed through the metal stent by using the forceps and basket. After complete removal of all solid debris from the cavity, a pigtail-type, nasobiliary drainage catheter was placed into the cyst. Then, the cysts were routinely lavaged with normal saline. The body temperature of the patients returned to normal after the procedure. The use of conventional tubular self-expandable metal stents (SEMS) for pseudocyst drainage has been previously reported [20, 2225]. Itoi et al. [20] used SEMS to resolve pseudocysts. All stents were successfully deployed without complications; the median time of placement was 35 days. There was no pseudocyst recurrence during median follow-up of 11.4 months. In the study of Talreja et al. [22], SEMS were used for drainage of PFC. Seventeen of 18 (95\%) patients responded successfully, with 14 (78\%) achieving complete resolution of their PFCs. In the study of Belle et al. [23], a special, self-expanding, partially covered, metal mesh stent was designed to keep the pancreaticogastrostomy open for drainage of walled-off necrosis and for further endoscopic necrosectomy. All the cases in that study had complete removal of necrotic masses without major complications. Leong et al. [24] reported a case with severe necrotizing gallstone pancreatitis complicated by infected pancreatic necrosis. Necrosectomy was performed to control the ongoing sepsis. Subsequently, there was a recurrence of an infected necrotic collection at the site of necrosectomy. Pancreatic duct stenting was performed to treat pancreatic duct leakage, followed by EUS-guided insertion of a fully covered SEMS to drain the infected fluid collection. There was rapid and complete clinical recovery. Wrobel et al. [25] used a new lumen-apposing metal stent to drain PFC and perform endoscopic necrosectomy. Success rate and PFC resolution were comparable to those with pigtail stents, with fewer complications. Seifert et al. [26] described the technique of endoscopic necrosectomy. After needle knife puncture and dilation from 8 to $20 \mathrm{~mm}$, Seifert achieved direct endoscopic access to the pancreatic necrosis [26]. In our study, double-flanged metal stents were used instead of double-pigtail stents in two cases. Endoscopic necrosectomy was performed though the metal stent. The metal stents were removed by using biopsy forceps under EUS guidance 12 weeks after placement; no complications occurred.

\section{Conclusions}

The cyst diameter was an independent risk factor for infection. Larger cysts with a diameter $>15 \mathrm{~cm}$ should perhaps be drained initially with multiple pigtail or a larger diameter self-expandable metal stents to try to avoid 
infection. Further studies of endoscopic drainage of PFC are indicated to define terminology and develop meaningful comparisons.

Acknowledgments We thank all of the doctors, nurses, and pathologists who participated in this study.

\section{Compliance with ethical standards}

Disclosures No conflict of interest has been declared by Jintao Guo, Linlin Feng, Siyu Sun, Nan Ge, Xiang Liu, Sheng Wang, Guoxin Wang, Beibei Sun.

Open Access This article is distributed under the terms of the Creative Commons Attribution 4.0 International License (http://crea tivecommons.org/licenses/by/4.0/), which permits unrestricted use, distribution, and reproduction in any medium, provided you give appropriate credit to the original author(s) and the source, provide a link to the Creative Commons license, and indicate if changes were made.

\section{References}

1. Varadarajulu S, Christein JD, Tamhane A, Drelichman ER, Wilcox CM (2008) Prospective randomized trial comparing EUS and EGD for transmural drainage of pancreatic pseudocysts (with videos). Gastrointest Endosc 68:1102-1111

2. Baron TH, Harewood GC, Morgan DE, Yates MR (2002) Outcome differences after endoscopic drainage of pancreatic necrosis, acute pancreatic pseudocysts, and chronic pancreatic pseudocysts. Gastrointest Endosc 56:7-17

3. Cahen D, Rauws E, Fockens P, Weverling G, Huibregtse K, Bruno M (2005) Endoscopic drainage of pancreatic pseudocysts: long-term outcome and procedural factors associated with safe and successful treatment. Endoscopy 37(10):977-983

4. Binmoeller KF, Weilert F, Shah JN, Bhat YM, Kane S (2013) Endosonography-guided transmural drainage of pancreatic pseudocysts using an exchange-free access device: initial clinical experience. Surg Endosc 27(5):1835-1839

5. Săftoiu A, Ciobanu L, Seicean A, Tantău M (2013) Arterial bleeding during EUS-guided pseudocyst drainage stopped by placement of a covered self-expandable metal stent. BMC Gastroenterol 13:93

6. Varadarajulu S, Bang JY, Sutton BS, Trevino JM, Christein JD, Wilcox CM (2013) Equal efficacy of endoscopic and surgical cystogastrostomy for pancreatic pseudocyst drainage in a randomized trial. Gastroenterology 145(3):583-590

7. Zerem E, Pavlović-Čalić N, Haračić B (2014) Comparative evaluation of outcomes of endoscopic versus percutaneous drainage for symptomatic pancreatic pseudocysts. Gastrointest Endosc 79(6): 1028

8. Rodriguez JR, Razo AO, Targarona J, Thayer SP, Rattner DW, Warshaw AL, Fernández-del Castillo C (2008) Debridement and closed packing for sterile or infected necrotizing pancreatitis: insights into indications and outcomes in 167 patients. Ann Surg 247:294-299

9. Akshintala VS, Saxena P, Zaheer A, Rana U, Hutfless SM, Lennon AM, Canto MI, Kalloo AN, Khashab MA, Singh VK (2014) A comparative evaluation of outcomes of endoscopic versus percutaneous drainage for symptomatic pancreatic pseudocysts. Gastrointest Endosc 79(6):921-928

10. Kahaleh M, Shami VM, Conaway MR, Tokar J, Rockoff T, De La Rue SA, de Lange E, Bassignani M, Gay S, Adams RB,
Yeaton P (2006) Endoscopic ultrasound drainage of pancreatic pseudocyst: a prospective comparison with conventional endoscopic drainage. Endoscopy 38:355-359

11. Varadarajulu S, Lopes TL, Wilcox CM, Drelichman ER, Kilgore ML, Christein JD (2008) EUS versus surgical cyst-gastrostomy for management of pancreatic pseudocysts. Gastrointest Endosc 68:649-655

12. Singhal S, Rotman SR, Gaidhane M, Kahaleh M (2013) Pancreatic fluid collection drainage by endoscopic ultrasound: an update. Clin Endosc 46(5):506-514

13. Baron TH (2007) Treatment of pancreatic pseudocysts, pancreatic necrosis, and pancreatic duct leaks. Gastrointest Endosc Clin N Am 17:559-579

14. Yin WY (2005) The role of surgery in pancreatic pseudocyst. Hepatogastroenterology 52:1266-1273

15. Puri R, Mishra SR, Thandassery RB, Sud R, Eloubeidi MA (2012) Outcome and complications of endoscopic ultrasound guided pancreatic pseudocyst drainage using combined endoprosthesis and naso-cystic drain. J Gastroenterol Hepatol 27:722-727

16. Baron TH, Harewood GC, Morgan DE, Yates MR (2002) Outcome differences after endoscopic drainage of pancreatic necrosis, acute pancreatic pseudocysts, and chronic pancreatic pseudocysts. Gastrointest Endosc 56:7-17

17. Hookey LC, Debroux S, Delhaye M, Arvanitakis M, Le Moine O, Devière J (2006) Endoscopic drainage of pancreatic fluid collections in 116 patients: a comparison of etiologies, drainage techniques, and outcomes. Gastrointest Endosc 63:635-643

18. Varadarajulu S, Bang JY, Phadnis MA, Christein JD, Wilcox CM (2011) Endoscopic transmural drainage of peripancreatic fluid collections: outcomes and predictors of treatment success in 211 consecutive patients. J Gastrointest Surg 15:2080-2088

19. Siddiqui A, DeWitt JM, Strongin A, Singh H, Jordan S, Loren DE, Kowalski T, Eloubeidi MA (2013) Outcomes of EUS-guided drainage of debris-containing pancreatic pseudocysts by using combined endoprosthesis and a nasocystic drain. Gastrointest Endosc 78(4):589-595

20. Itoi T, Binmoeller KF, Shah J, Sofuni A, Itokawa F, Kurihara T, Tsuchiya T, Ishii K, Tsuji Shujiro, Ikeuchi N, Moriyasu F (2012) Clinical evaluation of a novel lumen-apposing metal stent for endosonography-guided pancreatic pseudocyst and gallbladder drainage (with videos). Gastrointest Endosc 75(4):870-876

21. Rische S, Riecken B, Degenkolb J, Kayser T, Caca K (2013) Transmural endoscopic necrosectomy of infected pancreatic necroses and drainage of infected pseudocysts: a tailored approach. Scand J Gastroenterol 48(2):231-240

22. Talreja JP, Shami VM, Ku J, Morris TD, Ellen K, Kahaleh M (2008) Transenteric drainage of pancreatic fluid collections with fully covered self-expanding metallic stents (with video). Gastrointest Endosc 68:1199-1203

23. Belle S, Collet P, Post S, Kaehler G (2010) Temporary cystogastrostomy with self-expanding metallic stents for pancreatic necrosis. Endoscopy 42:493-495

24. Ang TL, Eu Kwek AB, Fock KM, Teo EK (2014) Endoscopic ultrasound-guided insertion of a large diameter fully covered selfexpandable metallic stent as rescue therapy for recurrent infected walled off pancreatic necrosis after surgical necrosectomy. Endosc Ultrasound 3:245-248

25. Wrobel PS, Kaplan J, Siddiqui AA (2014) A new lumen-apposing metal stent for endoscopic transluminal drainage of peripancreatic fluid collections. Endosc Ultrasound 3:203-204

26. Seifert H, Biermer M, Schmitt W, Jürgensen C, Will U, Gerlach R, Kreitmair C, Meining A, Wehrmann T, Rösch T (2009) Transluminal endoscopic necrosectomy after acute pancreatitis: a multicentre study with long-term follow-up (the GEPARD Study). Gut 58:1260-1266 